\title{
Recombinant PEP-1-SOD1 improves functional recovery after neural stem cell transplantation in rats with traumatic brain injury
}

\author{
JINMING JIA ${ }^{1}$, FEIFEI CHEN ${ }^{2}$ and YUNFEI WU ${ }^{3}$ \\ ${ }^{1}$ Department of Critical Care Medicine, The Putian Hanjiang Hospital, Putian, Fujian 351100; Departments of \\ ${ }^{2}$ Emergency and ${ }^{3}$ Pathology, The Third People's Hospital of Changzhou, Changzhou, Jiangsu 213001, P.R. China
}

Received August 3, 2015; Accepted December 9, 2016

DOI: $10.3892 /$ etm.2018.5781

\begin{abstract}
The transplantation of neural stem cells (NSCs) has been demonstrated as a potential treatment strategy for traumatic brain injury (TBI). $\mathrm{Cu}, \mathrm{Zn}$-superoxide dismutase (SOD1) is an important antioxidant enzyme that detoxifies intracellular reactive oxygen species, thereby protecting cells from oxidative damage. PEP-1, a peptide carrier, is able to deliver full-length native peptides or proteins into cells Therefore, the current study investigated the effect of the transplantation of NSCs in combination with PEP-1-SOD1 for the treatment of experimental TBI in rats. Initially, the effect of PEP-1-SOD1 on the proliferation of NSCs was evaluated by MTT assay. PEP-1-SOD1 $(0.5,2.5$ and $4.5 \mu \mathrm{M})$ significantly increased the proliferation rates of NSCs at 24, 48 and $72 \mathrm{~h}$ in a dose-dependent manner. PEP-1-SOD1 also promoted the differentiation of NSCs in vitro. The in vivo experiment showed that PEP-1-SOD1 in combination with NSC transplantation significantly improved the functional recovery of rats following TBI compared with NSC transplantation alone. A significant increase in brain aquaporin-4 (AQP4) mRNA and protein expression levels was observed 4 days post-TBI in PEP-1-SOD1, NSCs and PEP-1-SOD1 + NSCs groups compared with the saline group. The PEP-1-SOD1 + NSCs group showed a further increase of AQP4 mRNA and protein expression levels compared with the NSCs and PEP-1-SOD1 groups. In conclusion, the current data suggests that PEP-1-SOD1 may promote the proliferation and differentiation of NSCs, and thereby improve the functional recovery of TBI model rats following NSCs transplantation through upregulating the expression of AQP4.
\end{abstract}

Correspondence to: Dr Jinming Jia, Department of Critical Care Medicine, The Putian Hanjiang Hospital, 183 DingPu Road, Putian, Fujian 351100, P.R. China

E-mail: jjmdoctor@126.com

Key words: aquaporin-4, neural stem cells, superoxide dismutase, traumatic brain injury

\section{Introduction}

Traumatic brain injury (TBI) has a high incidence rate worldwide, and results in immediate neuronal and glial cell loss, in addition to associated neurological deficits (1). In recent years, neural stem cells (NSCs) have been used as a novel approach in the treatment of certain neurodegenerative disorders, as well as in the management of central neural system injuries (2). NSCs are able to self-renew and to differentiate into mature neuronal and glial cell types, and thereby have become a potential target for cell transplantation therapy following injury (3). A previous study showed that transplanted NSCs could significantly improve neurological function following TBI (4), suggesting NSC transplantation is a potential treatment strategy for TBI. However, the success of this approach has been limited, largely due to the complexity of the injury microenvironment (5).

TBI results in both primary and secondary injury to the brain (6). The primary injury leads to direct neural cell loss and necrotic cell death, while the secondary injury involves neuronal cell death following TBI, which exacerbates the damage from the primary injury (7). Oxidative stress, characterized by excessively produced reactive oxygen species (ROS), is one of the events that occurs subsequent to TBI that contributes to secondary neuronal cell death (8). After TBI, the increased level of cellular damage to cellular macromolecules caused by ROS, including that to proteins, DNA and membrane phospholipids, leads to lipoperoxidation of the cell membrane, resulting in the dysfunction of numerous structures and organelles, such as mitochondria. This then results in apoptotic cell death of neurons $(9,10)$. In the nervous system, superoxide dismutases (SODs) are important antioxidant enzymes involved in superoxide detoxification in normal cellular metabolism and after cell injury (11). Therefore, overexpression of SODs may improve the efficacy of the transplantation of NSCs in the treatment of TBI.

SOD1 is a specific antioxidant enzyme that is able to counteract superoxide anions. Transplantation of NSCs that overexpress SOD1 prolongs the survival of these grafted cells and enhances functional recovery in animal models of ischemic stroke and intracerebral hemorrhage $(12,13)$. PEP-1, a 21-residue peptide, has been used as a carrier for the 
delivery of biologically active molecules, such as SOD1, into cells $(14,15)$. PEP-1-SOD1 has been demonstrated to protect neurons from ROS once delivered to the site of the injury, and also to improve functional recovery after stroke or spinal cord injury $(14,15)$. The aforementioned studies suggest that PEP-1-SOD1 may also be a potential therapeutic agent for the treatment of TBI. Therefore, in the present study, the effect of the transplantation of NSCs in combination with PEP-1-SOD1 was investigated for the treatment of experimental TBI in rats, and the underlying mechanisms were assessed.

\section{Materials and methods}

Isolation and culture of NSCs. Brain tissue was isolated from embryonic 14-day-old fetal Sprague-Dawley (SD) rats as described in a previous study (16). The SD rats were purchased from the Experimental Animal Center of The Third People's Hospital of Changzhou (Changzhou, China). The rats were maintained in cages with free access to water and food, at a temperature of $25 \pm 2^{\circ} \mathrm{C}$ and humidity of $50 \pm 5 \%$, with a $12 \mathrm{~h} \mathrm{light/dark} \mathrm{cycle.} \mathrm{The} \mathrm{pia} \mathrm{mater} \mathrm{and} \mathrm{choroid} \mathrm{plexus} \mathrm{were}$ peeled off. The brain tissue was then cut into $\sim 1-\mathrm{mm}^{3}$ sections. DMEM/F12 medium (Gibco; Thermo Fisher Scientific, Inc., Waltham, MA, USA) was added to the shredded tissue and incubated for $10 \mathrm{~min}$ at room temperature. Gentle pipetting was used to generate a single cell suspension. The suspension was centrifuged for $10 \mathrm{~min}$ at $1,200 \mathrm{x}$ g, resuspended with culture medium supplemented with $2 \%$ B27, $20 \mathrm{ng} / \mathrm{ml}$ basic fibroblast growth factor and $20 \mathrm{ng} / \mathrm{ml}$ epidermal growth factor (all PeproTech, Inc., Rocky Hill, NJ, USA) and then seeded in $25-\mathrm{cm}^{2}$ T-flasks. Cells were maintained at $37^{\circ} \mathrm{C}$ in a humidified atmosphere with $5 \% \mathrm{CO}_{2}$. The experiments were approved by the Ethics Committee of the Third People's Hospital of Changzhou.

Expression and purification of PEP-1-SOD1 fusion protein. Construction of the PEP-1-SOD1 expression vector, expression of PEP-1-SOD1 in E. coli, and purification of the expressed fusion protein were performed according to a method described previously (15). Briefly, to produce the PEP-1-SOD1 fusion protein, the plasmid pET15b-PEP-1-SOD1 was transformed into E. coli and grown in $100 \mathrm{ml}$ Luria-Bertani medium (cat. no. 28200 ; Newborn Co. Ltd., Shenzhen, China) at $37^{\circ} \mathrm{C}$ to an optimal density (which was examined in the following experiments). Harvested cells were lysed by sonication at $4^{\circ} \mathrm{C}$ and cell extracts were centrifuged at $15,000 \mathrm{x}$ g for $10 \mathrm{~min}$ at $4^{\circ} \mathrm{C}$. The fusion protein was purified using an ProteoPrep Top 20 protein affinity column (Sigma-Aldrich; Merck Millipore, Darmstadt, Germany) according to the manufacturer's instructions. The protein concentration was determined by the BAC method using bovine serum albumin (cat. no. NIST927E; Sigma-Aldrich; Merck Millipore) as a standard.

MTT assay. The in vitro biological activity of PEP-1-SOD fusion proteins in NSCs was assessed by measuring the viability of NSCs. The cells were seeded into 96-well plates at a density of $1 \times 10^{5} / \mathrm{ml}$. The cells were pretreated with $0,0.5,2.5$ and $4.5 \mu \mathrm{M}$ PEP-1-SOD for 24, 48 or $72 \mathrm{~h}$. Subsequently, an MTT assay was performed according to a previously described method $(17,18)$.
Immunocytochemical analysis. To investigate the differentiation of the NSCs, immunocytochemistry was performed according to a previous method (19). In brief, cells were fixed with $4 \%$ paraformaldehyde. After washing with phosphate-buffered saline, NSCs were processed for immunohistochemical staining using cell-specific markers of differentiation via the detection of receptor interacting protein (RIP), neural nuclear antigen (NeuN) and glial fibrillary acidic protein (GFAP), using rabbit anti-rat RIP polyclonal antibody (cat. no. ab106393), rabbit anti-rat NeuN polyclonal antibody (cat. no. ab104225) and rabbit anti-rat GFAP polyclonal antibody (cat. no. ab7260), respectively (all 1:200; Abcam, Cambridge, UK). Lastly, the reaction was developed using 3,3'-diaminobenzidine (cat. no. D8001; Sigma-Aldrich; Merck Millipore), which resulted in brown-yellow staining. The cells were observed under a light microscope (BX51; Olympus, Tokyo, Japan).

Establishment of the TBI model. Male SD rats $(\mathrm{n}=80$; age, 2-3 months; weight, $250 \pm 10 \mathrm{~g}$ ) were purchased from Beijing HFK Bioscience Co. Ltd. (Beijing, China). The rats were housed with a $12 \mathrm{~h}$ dark/light cycle and were allowed free access to food and water. All the animals used in the study received humane care.

The TBI model was established according to a previously described method (20). Briefly, the rats were anesthetized with $7 \%$ chloral hydrate (Sigma-Aldrich; Merck Millipore) at a dose of $5 \mathrm{ml} / \mathrm{kg}$ by intraperitoneal (i.p.) injection. The rectal temperature was maintained within the range of $37 \pm 0.5^{\circ} \mathrm{C}$ with a heating pad. A right parietal craniotomy (diameter, $5 \mathrm{~mm}$ ) was conducted with a drill under aseptic conditions. The center of the craniotomy was $2 \mathrm{~mm}$ anterior to the lambdoid suture and $2 \mathrm{~mm}$ lateral to the skull midline. A contusion was produced by allowing a counterweight weighing $30 \mathrm{~g}$ to drop onto a piston resting on the dura from a height of $15 \mathrm{~cm}$ through a guide tube. After this trauma, the rats were returned to their cages, and the room temperature was maintained at $25 \pm 0.5^{\circ} \mathrm{C}$.

Treatment groups. At $24 \mathrm{~h}$ post trauma, the rats were randomly assigned into four groups as follows: i) Saline group, ii) NSCs group, iii) PEP-1-SOD1 group, and iv) NSCs + PEP-1-SOD1 group, with 20 animals in each group. The rats were anesthetized and the craniotomy was performed again. The rats were then treated with the NSC suspension or recombinant PEP-1-SOD1 as follows: i) Saline group, received $0.1 \mathrm{ml}$ saline injected at the injury site; ii) NSCs group, treated with $0.1 \mathrm{ml} \mathrm{NSC}$ suspension $\left(2 \times 10^{7} / \mathrm{ml}\right)$ injected at the site of injury; iii) PEP-1-SOD1 group, treated with $200 \mu \mathrm{g}$ PEP-1-SOD1 by i.p. injection; iv) NSCs + PEP-1-SOD1 group, treated with a $0.1 \mathrm{ml}$ NSC suspension $\left(2 \times 10^{7} / \mathrm{ml}\right)$ injected at the site of injury and $200 \mu$ g PEP-1-SOD1 by i.p. injection. The neurological function of the rats was assessed at designated times (days 1,3, 7, 14, 21 and 28 after TBI). Four days post-TBI, 6 rats in each group were anesthetized with 7\% chloral hydrate (Sigma-Aldrich; Merck Millipore; $5 \mathrm{ml} / \mathrm{kg}$, i.p.) and sacrificed by decapitation. The brain tissues were then isolated and frozen immediately in liquid nitrogen in preparation for the subsequent analyses.

Neurological function analysis (Bederson score). The first assessment was performed $30 \mathrm{~min}$ prior to treatment 
administration to verify the establishment of TBI. Any rat not displaying a score of $\geq 2$ was eliminated from the study.

The neurological function of each rat was carefully evaluated by members in a laboratory at the Department of Pathology, who were blinded to the group information using a modified Bederson score $(21,22)$ as follows: 0, no apparent neurological deficits; 1 , offside forelimb flexion; 2 , weakness of the offside forelimb gripping strength when holding the tail; 3 , circling to the left when holding the tail; 4 , circling to the left when moving freely.

Reverse transcription-quantitative polymerase chain reaction (RT-qPCR). Approximately $50-100 \mathrm{mg}$ brain tissue was homogenized in $1 \mathrm{ml}$ TRIzol reagent, and then centrifuged at $12,000 \mathrm{x} \mathrm{g}$ for $10 \mathrm{~min}$ at $4^{\circ} \mathrm{C}$. The supernatant was collected and total RNA was extracted. The RNA concentration was then measured and the purity was confirmed. Treatment with DNase (Invitrogen Life Technologies; Thermo Fisher Scientific, Inc.) was conducted prior to the RT reaction. A SuperScript III reverse transcription kit (cat. no. 18080093; Invitrogen Life Technologies; Thermo Fisher Scientific, Inc.) was used to convert RNA into cDNA at $4^{\circ} \mathrm{C}$, and then qPCR was performed using SYBR-Green I dye (cat. no. S7585; Invitrogen Life Technologies; Thermo Fisher Scientific, Inc.) using the FTC-2000 Real-Time Quantitative PCR system. The primers used in the experiments are as follows: aquaporin-4 (AQP4) forward, 5'-TCGCCAAGTCCGTCTTCTACA-3' and reverse, 5'-CCGTGGTGACTCCCAATCC-3'; $\beta$-actin forward, 5'-CCCATCTATGAGGGTTACGC-3' and reverse, 5'-TTT AATGTCACGCACGATTTC-3'. The PCR reaction system included $2 \mu \mathrm{l}$ cDNA, $2 \mu \mathrm{l}$ polymerase, $25 \mu \mathrm{l}$ 2X PCR buffer, $0.5 \mu 1$ 20X SYBR-Green I (all purchased from Invitrogen Life Technologies; Thermo Fisher Scientific, Inc.), $1 \mu 125 \mathrm{mM}$ forward and reverse primers and distilled water, to ensure the total volume of the mixture was $50 \mu 1$. The PCR program was as follow: $94^{\circ} \mathrm{C}$ for $4 \mathrm{~min}$, followed by $94^{\circ} \mathrm{C}$ for $20 \mathrm{sec}$, $60^{\circ} \mathrm{C} 30 \mathrm{sec}, 72^{\circ} \mathrm{C} 30 \mathrm{sec}$ and a total of 35 reaction cycles. The absence of non-specific products was verified after each run by melting curve analysis. The relative gene quantities were calculated by the $2^{-\Delta \Delta \mathrm{Cq}}$ method (23) in comparison with the expression levels of $\beta$-actin.

Western blot analysis. The tissues were lysed utilizing RIPA buffer $(1 \mathrm{ml} / 100 \mathrm{mg})$ at $0^{\circ} \mathrm{C}$, and centrifuged at a speed of $12,000 \mathrm{x} \mathrm{g}$ for $10 \mathrm{~min}$. The total protein concentration was determined using a BCA assay kit (cat. no. 23227; Pierce Biotechnology, Rockford, Illinois, USA) according to the instructions of the manufacturer. The total protein $(40 \mu \mathrm{g})$ was loaded for $15 \%$ SDS-PAGE electrophoresis, and then the proteins were transferred to PVDF membranes. The PVDF membranes were blocked with $5 \%$ non-fat dry milk at $37^{\circ} \mathrm{C}$ for $1 \mathrm{~h}$, and then incubated with anti-rat AQP4 (cat. no. ab156924; $1: 2,000 ;$ Abcam) or anti-rat $\beta$-actin (cat. no. ab8227; 1:2,000; Abcam) antibody at $4^{\circ} \mathrm{C}$ for $12 \mathrm{~h}$. Finally, the membranes were incubated with HRP-labeled goat anti-mouse IgG antibody (cat. no. ab6789; 1:1,000; Abcam) at $37^{\circ} \mathrm{C}$ for $1 \mathrm{~h}$. The immunoreactivity of the bands was detected using an enhanced chemiluminescence reagent (ECL; Amersham, Piscataway, New Jersey, USA) on X-ray film. The densities of AQP4 and $\beta$-actin were quantified using a Gel Image Analysis System
(Labworks 4.6; UVP LLC, Upland, CA, USA). The relative AQP4 expression was normalized to those of $\beta$-actin.

Immunocytochemistry assay. The cells were fixed using $4 \%$ paraformaldehyde for $24 \mathrm{~h}$. The endogenous peroxidase in the cells was inactivated by incubation with $3 \%$ hydrogen peroxide, and slices were blocked using 5\% BSA for $20 \mathrm{~min}$. The slices were incubated with rabbit anti-rat nestin polyclonal antibody (cat. no. ab93157; 1:2,000; Abcam) at $4^{\circ} \mathrm{C}$ overnight. The slices were then incubated with goat anti-rabbit peroxidase-conjugated IgG (cat. no. ab205718; 1:500; Abcam) at $25^{\circ} \mathrm{C}$ for $1 \mathrm{~h}$. Finally, the slices were immersed in alkaline phosphatase-labeled diaminobenzidine (DAB; ZSGB Bio Co., Ltd., Beijing, China). Finally, the images were analyzed utilizing a Medical Image Analysis system (HMIAS22000; Wuhan Champion Image Technology Co., Ltd., Wuhan, China).

Statistical analysis. All results are expressed as the means \pm standard deviation. SPSS statistical software for windows (version 17.0; SPSS, Inc., Chicago, IL, USA) was used to analyze the data. One-way analysis of variance was performed for multiple comparisons followed by Fisher's least significant difference post-hoc comparisons. $\mathrm{P}<0.05$ was considered to indicate a statistically significant difference.

\section{Results}

Isolation and identification of NSCs. Fetal rat central NSCs were isolated from the fetuses of rats on day 15 (Fig. 1A). The expression of nestin was detected by immunocytochemistry. As shown in Fig. 1B, positive nestin expression was observed in the isolated cells.

PEP-1-SOD1 promotes the proliferation and differentiation of NSCs in vitro. The effect of recombinant PEP-1-SOD1 protein on the proliferation of primary cultured rat NSCs was evaluated by MTT assay. PEP-1-SOD1 $(0.5,2.5$ and $4.5 \mu \mathrm{M})$ significantly increased the proliferation rates of NSCs compared with the control group at 24, 48 and $72 \mathrm{~h}$ in a dose-dependent manner $(\mathrm{P}<0.01$; Fig. 2). Among the three time points, treatment with PEP-1-SOD1 induced the highest proliferation rate at $48 \mathrm{~h}$.

In order to determine whether PEP-1-SOD1 was able to promote the differentiation of NSCs, the expression of RIP, NeuN and GFAP was detected by immunocytochemistry. As shown in Fig. 3, untreated cells showed a low rate of differentiation. Exposure to PEP-1-SOD1 resulted in an increase in the expression levels of RIP, NeuN and GFAP.

PEP-1-SOD1 improves the effect of NSCs transplantation on neurological recovery after TBI. Neurological functions of rats with TBI were evaluated on days 1, 3, 7, 14, 21 and 28 after treatment (Fig. 4). The Bederson score system reflects the neurological functions of rats following TBI and was used to assess post-traumatic neurological impairment. The functional recovery of rats in all groups began 3 days post-TBI and was observed to gradually improve at the subsequent time points. The Bederson score was decreased in the NSCs, PEP-1-SOD1 and NSCs + PEP-1-SOD1 groups on day 3 following TBI, although no significant difference was observed determined between these groups and saline group. At day 7 post-TBI, rats 

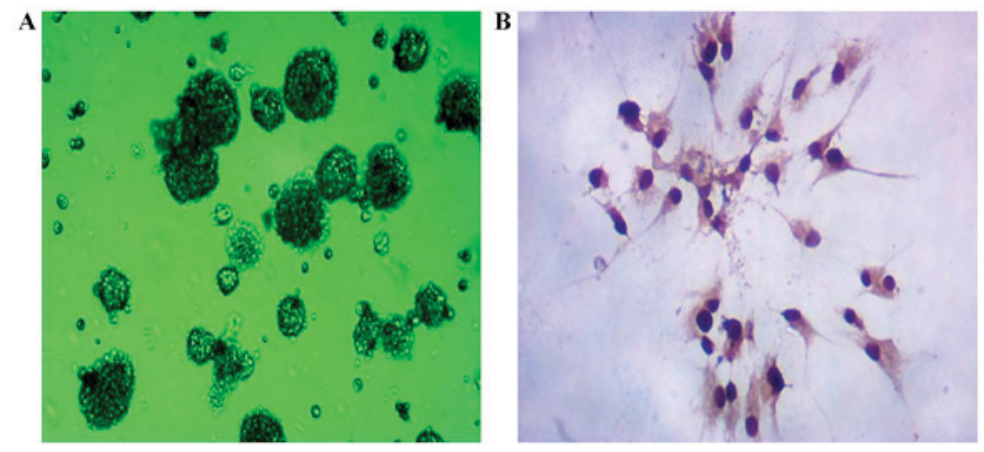

Figure 1. Isolation and identification of NSCs. (A) Isolated NSCs (magnification, $\mathrm{x} 40$ ) observed by light microscopy, and (B) the expression of nestin in NSCs as revealed by immunocytochemistry assay (magnification, $\mathrm{x} 400$ ). NSCs, neural stem cells.

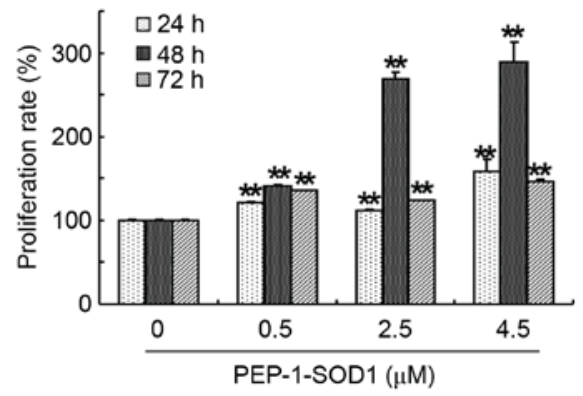

Figure 2. PEP-1-SOD1 promoted the proliferation of NSCs in vitro. NSCs incubated with different concentrations $(0,0.5,2.5$ and $4.5 \mu \mathrm{M})$ of PEP-1-SOD1 for the indicated times and the proliferation of the NSCs was examined using the MTT method. Data are expressed as mean \pm standard deviation ( $\mathrm{n}=3$ ). ${ }^{* *} \mathrm{P}<0.01$ vs. control group. NSCs, neural stem cells; SOD1, $\mathrm{Cu}, \mathrm{Zn}$-superoxide dismutase.

treated with NSCs + PEP-1-SOD1 showed a significantly lower Bederson score compared with rats treated with saline $(\mathrm{P}<0.05$; Fig. 4). The Bederson scores for the NSCs + PEP-1-SOD1 group were significantly decreased on days 21 and 28 after TBI, compared with those in the saline and NSCs groups ( $\mathrm{P}<0.01$; Fig. 4), suggesting that PEP-1-SOD1 improved the effect of NSC transplantation in the treatment of TBI.

PEP-1-SOD1 enhanced the effect of NSC transplantation on brain aquaporin-4 expression. AQP4 serves an important role in the formation of brain edema. Therefore, the effect of PEP-1-SOD1 in combination with NSCs on the expression of AQP4 in the brains of rats was determined (Fig. 5). Both PEP-1-SOD1 and NSCs transplantation significantly elevated the AQP4 mRNA and protein expression levels compared with those in saline-treated rats. In the NSCs + PEP-1-SOD1 group, the mRNA and protein expression levels of AQP4 were further increased compared with those in the PEP-1-SOD1 and NSCs groups $(\mathrm{P}<0.01$; Fig. 5$)$.

\section{Discussion}

The data of the present study indicated that recombinant PEP-1-SOD1 was able to promote the proliferation and differentiation of NSCs. Subsequently, the effect of PEP-1-SOD1 in combination with NSCs in rat models of TBI was investigated. PEP-1-SOD1 + NSC transplantation accelerated the functional recovery of neurological functions following TBI. Further experiments showed that PEP-1-SOD1 in combination with NSCs transplantation led to further increase in the mRNA and protein expression levels of AQP4.

The proliferation and differentiation of NSCs are key factors for NSC transplantation (24). It has been shown that chronic and acute oxidative stress may inhibit the proliferation of NSCs and the attenuation of oxidative damage may preserve the proliferation of NSCs (25). Therefore, SOD1 may serve an important role in protecting the proliferation of NSCs against oxidative damage. Thus, the current study determined the effect of recombinant PEP-1-SOD1 protein on the proliferation and differentiation of rat NSCs. The current data showed that treatment with three concentrations of PEP-1-SOD1 for 24, 48 and $72 \mathrm{~h}$ increased the proliferation of stem cells. PEP-1-SOD1 also promoted the expression of RIP, NEUN and GFAP in stem cell-derived neurons, suggesting that PEP-1-SOD1 is able to promote the differentiation of NSCs.

The Bederson score has been widely used for the assessment of functional recovery in studies concerning brain injury $(26,27)$. To obtain further information regarding the rats' recovery, the Bederson score was evaluated by a member of our laboratory, who was blinded to the group information, at 1, 3, 7, 14, 21 and 28 days after treatment. In the present study, the Bederson score was significantly increased in all the groups $24 \mathrm{~h}$ after TBI. Thereafter, the Bederson score in all the groups gradually decreased. The Bederson score in the NSCs + PEP-1-SOD1 group was lower compared with that of the control group from 7 days post-TBI. From 21 days post TBI, the Bederson score in the NSCs + PEP-1-SOD1 group was lower compared with that of the NSCs group. Cho et al (14) demonstrated that PEP-1-SOD1 treatment in ischemic animals displayed a neuroprotective effect in the ischemic hippocampus for an extended duration. In an intracerebral hemorrhage (ICH) mouse model, overexpression of SOD1 protected the grafted NSCs by decreasing the production of ROS (13). In addition, SOD1 overexpression resulted in progressive improvement in the behavioral recovery of mouse models of ICH (13). The current study suggests that PEP-1-SOD1 is able to promote the proliferation and differentiation of NSCs, and thereby facilitate the functional recovery of rats with TBI when administered in combination with NSC transplantation.

Brain edema is one of the hallmarks of TBI (28). AQP4, which is the water channel protein and the most abundant aquaporin in the brain, has been shown to have a dual role in the formation and resolution of edema after TBI (29). 


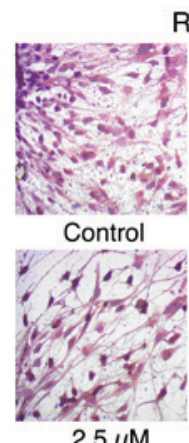

RIP
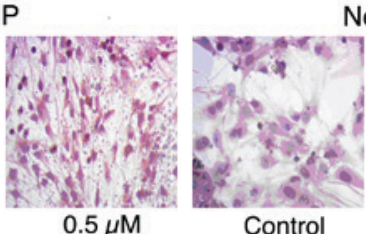

NeuN
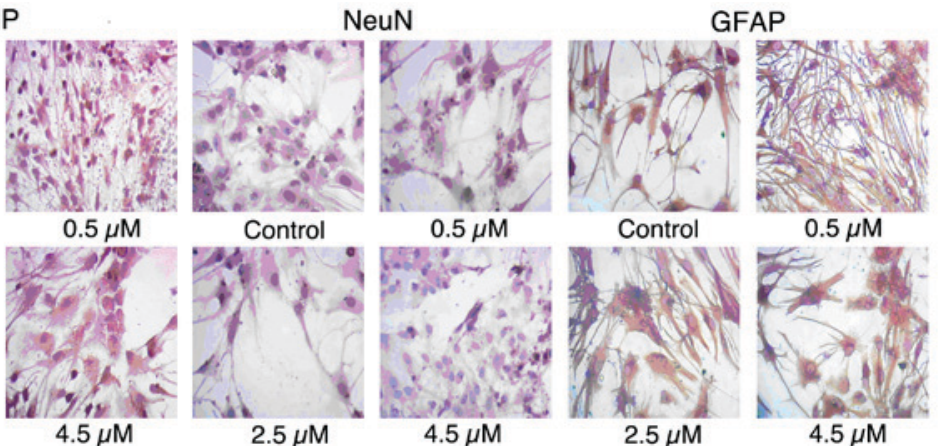

Figure 3. PEP-1-SOD1 promoted the differentiation of NSCs. NSCs were incubated with different concentrations (0, $0.5,2.5$ and $4.5 \mu \mathrm{M})$ of PEP-1-SOD1 for 6 days and then immunocytochemical staining was performed to detect the expression of RIP, NeuN and GFAP (magnification, x400). NSCs, neural stem cells; $\mathrm{SOD} 1, \mathrm{Cu}, \mathrm{Zn}$-superoxide dismutase; RIP, receptor interacting protein; NeuN, neural nuclear antigen; GFAP, glial fibrillary acidic protein.

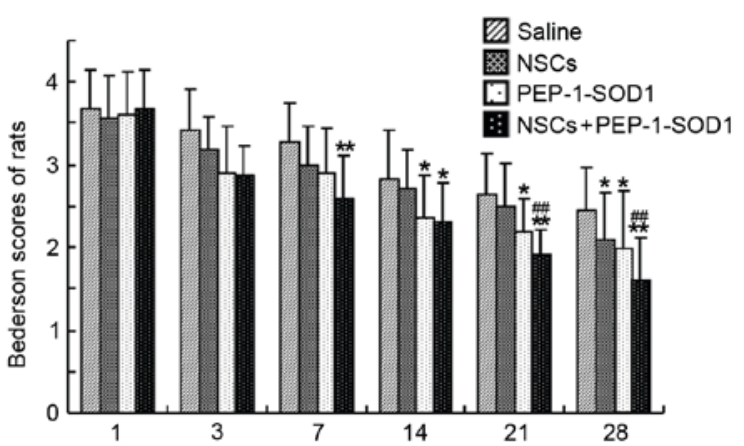

Figure 4. Bederson scores of rats at different time points. PEP-1-SOD1 promoted the neurological recovery after NSCs transplantation in TBI rats. Data are expressed as mean \pm standard deviation $(n=20$ for days 1 and $3 ; n=14$ for days 7 , 14,21 and 28 ). ${ }^{*} \mathrm{P}<0.05$ and ${ }^{* *} \mathrm{P}<0.01$ vs. control (saline) group; ${ }^{\# \#} \mathrm{P}<0.01$ vs. NSCs group. NSCs, neural stem cells; SOD1, $\mathrm{Cu}, \mathrm{Zn}$-superoxide dismutase.

The formation of brain edema is due to the disruption of the blood-brain barrier and the entrance of water due to the AQP4 protein (30). The mRNA and protein expression levels of AQP4 increase rapidly following TBI (31). In the early stages post-TBI, inhibition of AQP4 has positive effects in the prevention of edema formation $(32,33)$. AQP4 knockout in rats has been shown to exert a neuroprotective effect and improve functional recovery after TBI (34). However, in the late stages following TBI (a few days after the injury), AQP4 is important for the clearance of water from the brain to the blood vessels (35). Consistent with the results of a previous study (36), a significant increase in AQP4 was observed 4 days post-TBI in the PEP-1-SOD1, NSCs and PEP-1-SOD1 + NSCs groups compared with the control group. The PEP-1-SOD1 + NSCs group showed a further increase of AQP4 mRNA and protein expression levels compared with the NSCs + PEP-1-SOD1 group, suggesting that SOD1 may improve the effect of NSC transplantation on the functional recovery of TBI rats through upregulating AQP4 expression.

Although this study generated some notable results, there were also a few limitations. Firstly, the animal model used is limited, which may affect the precision of the results. Secondary, the mechanism underlying the effect of PEP-1-SOD1 on the functional recovery following neural stem cell transplantation in rats has not been fully clarified.

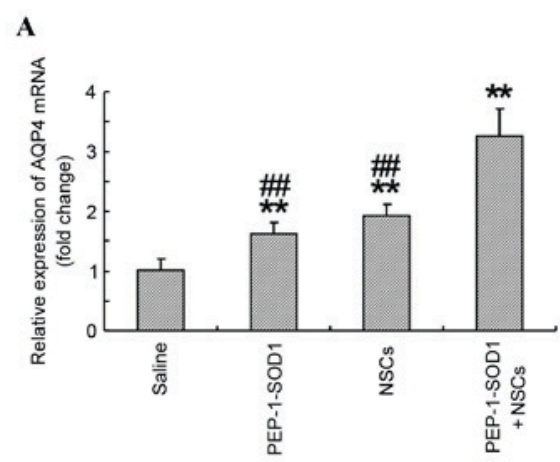

B
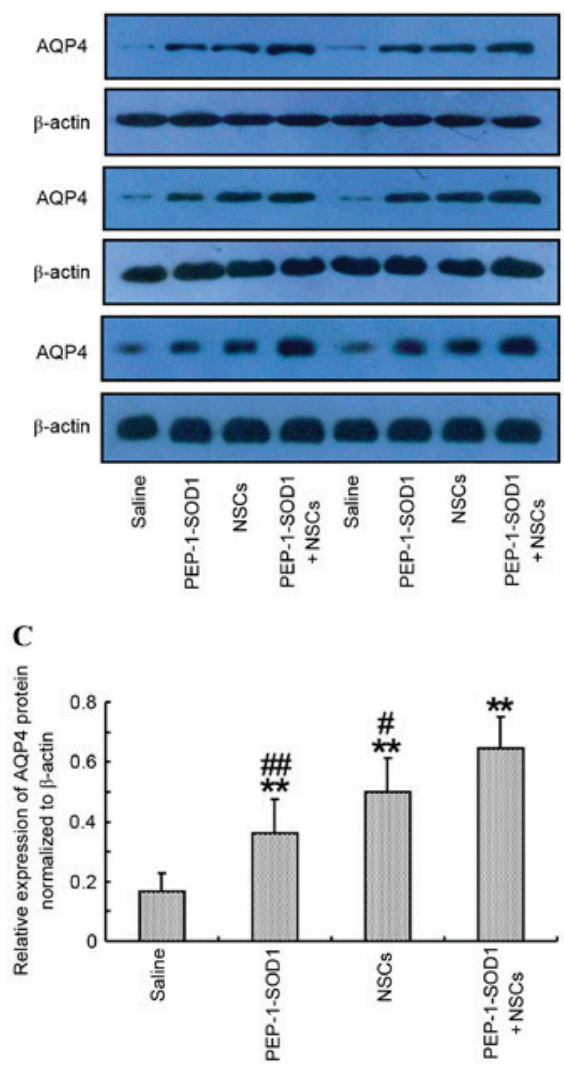

Figure 5. PEP-1-SOD1 enhanced the effect of NSC transplantation on brain AQP4 expression. (A) Reverse transcription-quantitative polymerase chain reaction analysis of AQP4 mRNA expression; (B) western blot analysis of AQP4 expression; and (C) quantitative data from the densitometric analysis of AQP4 expression. Data are expressed as mean \pm standard deviation $(\mathrm{n}=6){ }^{* * *} \mathrm{P}<0.01$ vs. control (saline) group; ${ }^{\#} \mathrm{P}<0.05$ and ${ }^{\# \#} \mathrm{P}<0.01$ vs the PEP-1-SOD1 + NSCs group. NSCs, neural stem cells; SOD1, Cu,Zn-superoxide dismutase; AQP4, aquaporin-4. 
Thirdly, other factors associated with the potential neuroprotective effect on functional recovery have not been investigated. In future studies, a larger number of animals may be used to investigate the effects of PEP-1-SOD-1 or other factors on functional recovery. Furthermore, the specific mechanism responsible for the effects of PEP-1-SOD-1 on the functional recovery also merit investigation in a further study.

In conclusion, SOD1 may promote the proliferation and differentiation of NSCs and thereby improve the functional recovery of TBI rats following NSC transplantation. SOD1 also further increased the expression levels of AQP4 after NSCs transplantation to facilitate the efflux of water into the blood, and subsequently accelerate the regression of brain edema. The current data indicates that recombinant SOD1 in combination with NSC transplantation is a promising potential therapy for TBI.

\section{References}

1. Moppett IK: Traumatic brain injury: Assessment, resuscitation and early management. Br J Anaesth 99: 18-31, 2007.

2. Rossi F and Cattaneo E: Opinion: Neural stem cell therapy for neurological diseases: Dreams and reality. Nat Rev Neurosci 3: 401-409, 2002.

3. Xiong Z, Zhao S, Mao X, Lu X, He G, Yang G, Chen M, Ishaq $\mathrm{M}$ and Ostrikov K: Selective neuronal differentiation of neural stem cells induced by nanosecond microplasma agitation. Stem Cell Res 12: 387-399, 2014.

4. Ma H, Yu B, Kong L, Zhang Y and Shi Y: Transplantation of neural stem cells enhances expression of synaptic protein and promotes functional recovery in a rat model of traumatic brain injury. Mol Med Rep 4: 849-856, 2011.

5. Addington CP, Roussas A, Dutta D and Stabenfeldt SE: Endogenous repair signaling after brain injury and complementary bioengineering approaches to enhance neural regeneration. Biomark Insights 10 (Suppl 1): S43-S60, 2015.

6. Lozano D, Gonzales-Portillo GS, Acosta S, de la Pena I, Tajiri N, Kaneko Y and Borlongan CV: Neuroinflammatory responses to traumatic brain injury: Etiology, clinical consequences and therapeutic opportunities. Neuropsychiatr Dis Treat 11: 97-106, 2015.

7. Kabadi SV and Faden AI: Neuroprotective strategies for traumatic brain injury: Improving clinical translation. Int $\mathrm{J}$ Mol Sci 15: 1216-1236, 2014.

8. Dasuri K, Zhang L and Keller JN: Oxidative stress, neurodegeneration, and the balance of protein degradation and protein synthesis. Free Radic Biol Med 62: 170-185, 2013.

9. Mutinati M, Pantaleo M, Roncetti M, Piccinno M, Rizzo A and Sciorsci RL: Oxidative stress in neonatology: A review. Reprod Domest Anim 49: 7-16, 2014.

10. Wang JW, Wang HD, Cong ZX, Zhou XM, Xu JG, Jia Y and Ding Y: Puerarin ameliorates oxidative stress in a rodent model of traumatic brain injury. J Surg Res 186: 328-337, 2014.

11. Peluffo $H$, Acarin L, Faiz M, Castellano $B$ and Gonzalez B: $\mathrm{Cu} / \mathrm{Zn}$ superoxide dismutase expression in the postnatal rat brain following an excitotoxic injury. J Neuroinflammation 2: 12, 2005.

12. Sakata H, Niizuma K, Wakai T, Narasimhan P, Maier CM and Chan PH: Neural stem cells genetically modified to overexpress cu/zn-superoxide dismutase enhance amelioration of ischemic stroke in mice. Stroke 43: 2423-2429, 2012.

13. Wakai T, Sakata H, Narasimhan P, Yoshioka H, Kinouchi $H$ and Chan PH: Transplantation of neural stem cells that overexpress SOD1 enhances amelioration of intracerebral hemorrhage in mice. J Cereb Blood Flow Metab 34: 441-449, 2014.

14. Cho JH, Hwang IK, Yoo KY, Kim SY, Kim DW, Kwon YG, Choi SY and Won MH: Effective delivery of Pep-1-cargo protein into ischemic neurons and long-term neuroprotection of Pep-1-SOD1 against ischemic injury in the gerbil hippocampus. Neurochem Int 52: 659-668, 2008.
15. Yune TY, Lee JY, Jiang MH, Kim DW, Choi SY and Oh TH: Systemic administration of PEP-1-SOD1 fusion protein improves functional recovery by inhibition of neuronal cell death after spinal cord injury. Free Radic Biol Med 45: 1190-1200, 2008.

16. Piao J, Major T, Auyeung G, Policarpio E, Menon J, Droms L, Gutin P, Uryu K, Tchieu J, Soulet D and Tabar V: Human embryonic stem cell-derived oligodendrocyte progenitors remyelinate the brain and rescue behavioral deficits following radiation. Cell Stem Cell 16: 198-210, 2015.

17. Kabeer FA, Sreedevi GB, Nair MS, Rajalekshmi DS, Gopalakrishnan LP, Kunjuraman $\mathrm{S}$ and Prathapan R: Antineoplastic effects of deoxyelephantopin, a sesquiterpene lactone from Elephantopus scaber, on lung adenocarcinoma (A549) cells. J Integr Med 11: 269-277, 2013.

18. Li Y, Wang X, Cheng S, Du J, Deng Z, Zhang Y, Liu Q, Gao J, Cheng B and Ling C: Diosgenin induces G2/M cell cycle arrest and apoptosis in human hepatocellular carcinoma cells. Oncol Rep 33: 693-698, 2015.

19. Yao ZG, Sun XL, Li P, Liu HL, Wu HL, Xi ZQ and Zheng ZH: Neural stem cells transplantation alleviate the hyperalgesia of spinal cord injured (SCI) associated with down-regulation of BDNF. Int J Clin Exp Med 8: 404-412, 2015.

20. Zhao J, Chen N, Shen N, Zhao H, Wang D, Shi J, Wang Y, Cui X, Yan Z and Xue H: Transplantation of human umbilical cord blood mesenchymal stem cells to treat a rat model of traumatic brain injury. Neural Regen Res 7: 741-748, 2012

21. Crumrine RC, Marder VJ, Taylor GM, Lamanna JC, Tsipis CP, Scuderi P, Petteway SR Jr and Arora V: Intra-arterial administration of recombinant tissue-type plasminogen activator (rt-PA) causes more intracranial bleeding than does intravenous rt-PA in a transient rat middle cerebral artery occlusion model. Exp Transl Stroke Med 3: 10, 2011.

22. Bederson JB, Pitts LH, Tsuji M, Nishimura MC, Davis RL and Bartkowski H: Rat middle cerebral artery occlusion: Evaluation of the model and development of a neurologic examination. Stroke 17: 472-476, 1986.

23. Arocho A, Chen B, Ladanyi M and Pan Q: Validation of the 2-DeltaDeltaCt calculation as an alternate method of data analysis for quantitative PCR of BCR-ABL P210 transcripts. Diagn Mol Pathol 15: 56-61, 2006.

24. Ryu HH, Lim JH, Byeon YE, Park JR, Seo MS, Lee YW, Kim WH, Kang KS and Kweon OK: Functional recovery and neural differentiation after transplantation of allogenic adipose-derived stem cells in a canine model of acute spinal cord injury. J Vet Sci 10: 273-284, 2009.

25. Takemura S, Kayama T, Kuge A, Ali H, Kokubo Y, Sato S, Kamii H, Goto K and Yoshimoto T: Correlation between copper/zinc superoxide dismutase and the proliferation of neural stem cells in aging and following focal cerebral ischemia. J Neurosurg 104: 129-136, 2006.

26. Sun F, Jin K and Uteshev VV: A type-II positive allosteric modulator of $\alpha 7 \mathrm{nAChRs}$ reduces brain injury and improves neurological function after focal cerebral ischemia in rats. PLoS One 8: e73581, 2013.

27. Crumrine RC, Marder VJ, Taylor GM, Lamanna JC, Tsipis CP, Novokhatny V, Scuderi P, Petteway SR Jr and Arora V: Safety evaluation of a recombinant plasmin derivative lacking kringles 2-5 and rt-PA in a rat model of transient ischemic stroke. Exp Transl Stroke Med 4: 10, 2012.

28. Marmarou A: Pathophysiology of traumatic brain edema: Current concepts. Acta Neurochir Suppl 86: 7-10, 2003.

29. Badaut J, Ashwal S and Obenaus A: Aquaporins in cerebrovascular disease: A target for treatment of brain edema? Cerebrovasc Dis 31: 521-531, 2011.

30. Panikashvili D, Shein NA, Mechoulam R, Trembovler V, Kohen R, Alexandrovich A and Shohami E: The endocannabinoid 2-AG protects the blood-brain barrier after closed head injury and inhibits mRNA expression of proinflammatory cytokines. Neurobiol Dis 22: 257-264, 2006.

31. Lopez-Rodriguez AB, Acaz-Fonseca E, Viveros MP and Garcia-Segura LM: Changes in cannabinoid receptors, aquaporin 4 and vimentin expression after traumatic brain injury in adolescent male mice. Association with edema and neurological deficit. PLoS One 10: e0128782, 2015.

32. Ding Z, Zhang J, Xu J, Sheng G and Huang G: Propofol administration modulates AQP-4 expression and brain edema after traumatic brain injury. Cell Biochem Biophys 67: 615-622, 2013. 
33. Cui T and Zhu G: Ulinastatin attenuates brain edema after traumatic brain injury in rats. Cell Biochem Biophys 71: 595-600, 2015.

34. Fukuda AM, Adami A, Pop V, Bellone JA, Coats JS, Hartman RE, Ashwal S, Obenaus A and Badaut J: Posttraumatic reduction of edema with aquaporin-4 RNA interference improves acute and chronic functional recovery. J Cereb Blood Flow Metab 33: 1621-1632, 2013.

35. Fukuda AM and Badaut J: Aquaporin 4: A player in cerebral edema and neuroinflammation. J Neuroinflammation 9: 279, 2012 .
36. Tourdias T, Mori N, Dragonu I, Cassagno N, Boiziau C, Aussudre J, Brochet B, Moonen C, Petry KG and Dousset V: Differential aquaporin 4 expression during edema build-up and resolution phases of brain inflammation. J Neuroinflammation 8: 143, 2011.

cc) (i) () $\odot$ This work is licensed under a Creative Commons cc) Attribution-NonCommercial-NoDerivatives 4.0 International (CC BY-NC-ND 4.0) License. 